\title{
Sınıf Öğretmenlerinin Yenilenen Hayat Bilgisi Programı Hakkındaki Görüşlerinin İncelenmesi
}

\section{Taner ALTUN*, Tekin GÜLER ${ }^{* *}$}

Öz: Değişim, bir zaman dilimi içindeki değişikliklerin bütünü olup, yaşamın kaçınılmaz parçalarından biridir. Değişimin bir doğrultusu olmadığında ileriye dönük ya da geriye dönük olabilir. Hayatın her alanında olduğu gibi, eğitimde de değişim kaçınılmaz olup, bu değişimden etkilenenlerden biri de Hayat Bilgisi Öğretim Programıdır. Bu çalışmanın amacı sınıf öğretmenlerinin 2017 yılında düzenlenen Hayat Bilgisi Öğretim Programına yönelik görüşlerini belirlemektir. Çalışma, nitel araştırma yöntemlerinden biri olan durum çalışması olarak yürütülmüştür. Çalışmada Kartopu örnekleme yöntemi kullanılmıştır. Çalışma, 38 Öğretmen ile yürütülmüştür. Veri toplamak amacıyla araştırmacı tarafından geliştirilen yarı yapılandırılmış görüşme formu kullanılmıştır. Elde edilen veriler, içerik analizi yoluyla çözümlenmiştir. Araştırmanın sonunda, program çerçevesinde hazırlanan ders kitabındaki örneklerin günlük yaşamla benzeşmediği, programdaki kazanımların bazılarının soyut olduğu, bu kazanımların gerçek yaşama aktarımı zor olduğu öğretmenler tarafından belirtilen görüşlerdendir. Ayrıca, yenilenen bu programın köy çocuklarına uygun olarak düzenlenmediği belirtilmiş ve öğretmenler tarafından programın içeriğine yönelik öneriler ortaya koyulmuştur. Araştırma sonuçlarına göre bazı önerilerde bulunulmuştur.

Anahtar sözcükler: İlkokul, program, hayat bilgisi, öğretim programı

\footnotetext{
* Doç. Dr. Trabzon Üniversitesi, ORCID: 0000-0001-9946-7257, taneraltun@gmail.com

**Öğr. Gör. Yozgat Bozok Üniversitesi, ORCID ID:0000-0003-4300-2228, tekin.guler@bozok.edu.tr
}

Gönderim:26.02.2019 Kabul:18.10.2019 Yayın: 02.01.2020




\section{Investigation of Classroom Teachers' Views on the Renewed Life Science Program}

Abstract: Change is the whole of changes in a time frame and is an inevitable part of life. It may be forward-looking or backward when there is no direction of change. As in all areas of life, change in education is inevitable. One of those who have changed as in every field of life is the Life Science Teaching Program. The aim of this study is to determine the opinions of the classroom teachers about the Life Science Curriculum that was changed in 2017. The study was carried out as a case study which is one of the qualitative research methods. Snowball sampling method was used in the study. The study was conducted with 38 teachers. The semistructured interview form developed by the researcher was used to collect data. The data were analyzed by content analysis. At the end of the study, it is stated by the teachers that the examples in the textbook prepared in the framework of the program are not similar to daily life, and some of the achievements in the program are abstract, and these gains are difficult to transfer to real life. Furthermore, it was stated that this renewed program was not designed for the children of the village and the suggestions were given by the teachers regarding the content of the program. Some suggestions were made according to the results of the research.

Keywords: Primary school, curriculum, life science, curriculum

\section{Giriş}

Değişim, bir zaman dilimi içindeki değişikliklerin bütünü (Türk Dil Kurumu, 2017) olup, yaşamın kaçınılmaz unsurlarından biridir (Fitcher, 2001). Değişimin hiçbir doğrultusu olmadığından, ileriye dönük ya da geriye dönük olabilir (Tezcan, 1984). Hayatın her alanında olduğu gibi eğitimde de değişim kaçınılmazdır. Eğitim programları, ulusal ya da uluslararası düzeyde kaliteli bir eğitim sistemi kurma, kalkınmayı sağlayabilecek nitelikli insan gücü yetiştirme, toplumsal ve kültürel değerlerin korunmasını ve geliştirilmesini temin etme gibi amaçlarla düzenlenmektedir (Özdemir, 2009). Türkiye'de uygulanmakta olan öğretim programlarının, bilim ve teknolojideki gelişmeler, bilgi toplumuna geçiş süreci, yetişmiş insan gücü ihtiyacı ve Avrupa Birliği’ne uyum süreci gibi sebeplerle yapıldığı bilinmektedir (Turan, 2006). Türkiye'deki öğretim programlarında belirli dönemler içerisinde farklı düzenlemeler 
yapıldığını görmekteyiz. Bu doğrultuda, Cumhuriyetin kuruluşundan bu yana defalarca öğretim programları ve eğitim sistemleri değişikliklere uğramıştır. Söz konusu değişikliklere uğrayanlardan biri de Hayat Bilgisi Öğretim Programıdır.

Türk Eğitim Sisteminin bir parçası olan ve ilkokulun ilk üç sınıfında okutulan Hayat Bilgisi dersi, toplu öğretim yaklaşımına dayalı olarak oluşturulmuş olup, çocukların hem kendilerini hem de içinde yaşadıkları toplumu ve dünyayı tanımaları için tasarlanmıştır. $\mathrm{Bu}$ ders, 1924, 1936, 1948, 1968, 1998, 2005 ve 2009 ilköğretim programlarında yer almıştır (MEB, 2009). Farklı yıllarda hazırlanan veya düzenlenen Hayat Bilgisi Öğretim Programında farklı anlayışlar hâkim olsa da 2005 yılında geleneksel anlayıştan vazgeçilerek yapılandırmacı öğrenme yaklaşımı benimsenmiştir (Turan, 2006).

Yapılandırmacı öğrenme yaklaşımı ve bu yaklaşımın tercih edilme sebepleri 2009 Hayat Bilgisi Öğretim Programı ve Kılavuzunda yer almış olup, söz konusu programda şöyle denilmektedir; her öğrenci okula kendi deneyimlerini, alışkanlıklarını ve beğenilerini beraberinde getirdikleri için bütün öğrencilerin aynı konuları aynı şekilde ve aynı düzeyde öğrenmeleri beklenemez. Başka bir ifadeyle, her öğrenci kendisine sunulan uyarıcıları kendi deneyimlerine bağlı olarak anlamlandırır ve bilgiyi kendine göre yapılandırır. Bu durum, her öğrenciye kendi öğrenmesinden sorumlu olmasını gerektirir. Yapılandırmacı kuram, öğreneni merkeze alan bir kuramdır. Çünkü her birey yeni bir bilgiyi, önceki bilgi, beceri ve yaşantılarının süzgecinden geçirerek yeniden yorumlamakta ve bilgiyi kendi zihninde oluşturmaktadır. Bu anlayışa göre öğrenme, eski bilgilerimizin yeni deneyim ve yaşantıların ışı̆̆ında yeniden yorumlanması ve yapılandırılmasıdır (Milli Eğitim Bakanlığı [MEB], 2009).

Yapılandırmacı yaklaşımın hakim olduğu 2009 Hayat Bilgisi Dersi Programında, insan, biyolojik, psikolojik, sosyal ve kültürel yönleriyle bir bütün olarak ve değişimin hem öznesi hem de nesnesi olarak ele alınmıştır. Bu noktadan hareketle "birey", "toplum” ve "doğa” olmak üzere üç ana öğrenme alanı belirlenmiş, değişim de bütün bu öğrenme alanlarını kuşatan daha genel bir boyut olarak düşünülmüş̧ür. Gerçek yaşamda bu öğrenme alanlarının içerikleri ve değişim iç içedir; bunlar sadece eğitim-öğretim amacıyla yapay olarak birbirinden ayrılabilir. Hayat bilgisi dersi için özellikle benimsenen toplu öğretim yaklaşımının da bir gereği olarak, 
bu öğrenme alanlarını aynı anda kuşatabilen "Okul Heyecanım”, "Benim Eşsiz Yuvam” ve “Dün, Bugün, Yarın” isimli üç tema belirlenmiştir (MEB, 2009).

Son olarak 2017 yılında mevcut müfredatlar, öğrenme öğretme teori ve yaklaşımlarındaki yenilik ve gelişmeler doğrultusunda çağın gerekliliklerini, ferdin ve toplumun değişen ihtiyaçlarını karşılayacak şekilde yenilenmiştir (MEB, 2017). Bu kapsamda Hayat Bilgisi Öğretim Programında da değişikliğe gidilmiştir. 2017 İlkokul Hayat Bilgisi Dersi Öğretim Programının geliştirilme sürecinde, dersle ilgili akademisyen, öğretmen ve uzmanlardan oluşan komisyon üyeleri tarafından yapılan çalışmalardan yararlanılmıştır (MEB, 2017). Hazırlanan taslak programlar 13 Ocak- 10 Şubat 2017 tarihleri arasında Milli Eğitim Bakanlığının resmi internet sitesinde askıya çıkarılmış ve anılan tarihler arasında toplumun her kesiminden kişilerin, kurum ve kuruluşların görüşleri alınmıştır. Söz konusu program incelendiğinde, programın amacının daha açık ve anlaşılabilir hale getirildiği, 2015 yılındaki öğretim programında 22 olan beceri sayısının "kariyer bilinci geliştirme" becerisi de eklenerek 23 yapıldı̆̆ı, 2015 yılı Öğretim Programında 20 değer varken, programda var olan "hoşgörü", "öz güven" değerleri çıkartılarak yerlerine "aile birliğine önem verme", bağımsızlık", "dostluk" ve "vefa" değerleri eklenerek değer sayısının 2017 yılında 21'e çıkarıldığı, programın giriş kısmında değerler eğitimi için ayrı bir başlık açılarak, değerlerin müfredatlarda yer alma nedenleri, nasıl yer aldığı, öğrenme öğretme sürecinde öğrencilere nasıl aktarılabileceği, değerler verilirken hangi öğretim yöntem ve tekniklerinin kullanılmasının gerektiğine ilişkin açıklamalara yer verildiği, tematik yaklaşımdan vazgeçildiği bunun yerine ünite sistemine dönüldüğü, var olan ünite isimlerini değiştiği, birinci sınıflarda kazanım sayılarının azaltıldığı, ikinci sınıflarda kazanım sayılarının artırılıp üçüncü sınıflarda kazanım sayılarının sabit tutulduğu anlaşılmaktadır. Ayrıca, iş sağlığı ve güvenliği konuları da kazanımlarla ilişskilendirilmiş, derse yönelik kazanımlar diğer derslerde yer alan kazanımlarla ilişkilendirilerek bütünlük sağlanmıştır.

Eğitim programlarında ihtiyaca yönelik olarak yapılan değişiklikler hiç şüphesiz eğitim-öğretim faaliyetlerinin ilgili tüm taraflarını etkiler. Eğitim öğretim faaliyetleri odağında birey olduğundan ve toplumun tüm kesimlerini yakından ilgilendirdiğinden bu alanda yapılan değişikliklerin çok özenli, dikkatli, planlı ve programlı olarak yapılması gerekmektedir. Nitekim yapılan bu değişikliğin topluma olumlu yansıması, daha önceden var olan sorun veya 
problemlere çözüm olması ya da bu problemlerin etkisini azaltması, eğitim-öğretim faaliyetlerinin tüm taraflarını tatmin edici nitelikte olmalıdır. Bu denli önemli bir mesele olan eğitim sisteminde veya öğretim programında yapılan değişikliklerin iyi izlenmesi eksik veya hatalı yönlerinin görülmesi ve zaman kaybetmeden düzeltilmesi gerekmektedir. Bu bakımdan bu çalışmada sınıf öğretmenlerinin Hayat Bilgisi Programına yönelik görüşleri nelerdir? sorusuna cevap aranacaktır. Bu çalışmanın amacı sınıf öğretmenlerinin 2017 yılında değiştirilen Hayat Bilgisi Öğretim Programına yönelik görüşlerini belirlemektir. Bu amaç kapsamında şu alt amaçlara da cevap bulunmaya çalışılacaktır;

Öğretmenlerin;

1. Program hazırlama komisyonlarına ve tanıtım kurslarına seminerlerine katılıp katılmadıkları,

2. Yeni programı yeterince inceleyip inceleyemedikleri,

3. Yeni programı uygulamak için yeterince materyallerinin olup olmadığg,

4. Yeni programla eski program arasında hangi farklılıkların olduğu ve yeni programla getirilen en önemli değişikliklerin neler olduğu ile bu değişikliklerin öğrenciye nasıl yansıyacağı,

5. Yeni programın uygulama açısından eskiye göre hangi kolaylık ve zorlukları getireceğidir.

\section{Yöntem}

\section{Araştırma Metodu}

Sınıf öğretmenlerinin 2017 yılında değiştirilen Hayat Bilgisi Öğretim Programına yönelik görüşlerini belirlemeyi amaçlayan bu çalışma, nitel araştırma yaklaşımı çerçevesinde oluşturulmuş olup, nitel araştırma, olgu ve olayları gözlemlenebilir, ölçülebilir ve sayısal olarak ifade edilebilir olarak ortaya koyan araştırma yaklaşımıdır (Yıldırım ve Şimşek, 2006). $\mathrm{Bu}$ araştırma yaklaşımı çerçevesinde durum çalışması kullanılmıştır. Durum çalışması, bir veya birkaç duruma ilişkin bütün etmenlerin bütüncül bir bakış açısıyla incelenerek bu durum ya da durumlara nasıl bir etkilerinin olduğunun belirlenmesidir (Yıldırım ve Şimşek, 2006). 
$\mathrm{Bu}$ araştırma yönteminin seçilme sebebi araştırma amacına uygun olmasıdır. Çünkü, 2017 Hayat Bilgisi Öğretim Programında yapılan değişikliklerin öğretmenler tarafından değerlendirilmesi bir durumdur.

\section{Çalışma Grubu}

Çalışmada kartopu örnekleme yöntemi kullanılmıştır. Kartopu örneklemede öncelikle evrene ait birimlerden biri ile temas kurularak, o birimin aracılığıyla diğer birimlerle temas kurulur. Bu işlem bir kartopunun büyümesi şeklindedir (Yazıcıoğlu ve Erdoğan, 2004). Çalışma kapsamında öncelikle beş öğretmenle iletişim kurulmuş ve onlar aracılığıyla diğer öğretmenlerle temasa geçilmiştir. $\mathrm{Bu}$ beş öğretmenin farklı bölgelerden olmasına özen gösterilmiş olup sonrasında herhangi bir müdahalede bulunulmamıştır. Çalışma kapsamında 45 öğretmenle iletişim kurulmuş ancak yedi öğretmenin isteksiz olmasından dolayı çalışma 38 öğretmenle gerçekleştirilmiştir.

\section{Veri Toplama Araçları}

Çalışmada elde edilen veriler araştırmacı tarafından yarı yapılandırılmış görüşme aracılığı ile toplanmıştır. Araştırmacı tarafından hazırlanan yarı yapılandırılmış görüşme formu 4 dört farklı uzmana incelettirilerek görüşleri alınmış ve forma son şekli verilmiştir. Çalışma grubunu oluşturan öğretmenlerin görev yaptıkları yerlerin coğrafi konumları ve birbirlerinden uzak olması bu durumda her biri ile yüz yüze yapılacak görüşmelerin ekonomik olmayacağı düşünülmüş olup, gelişen teknolojinin imkânlarından yararlanılarak görüşmeler telefon, mail ve sosyal medya aracılığı ile gerçekleşmiştir. Araştırmaya katılan 38 öğretmenin 20 kişisiyle telefon aracılığıyla, 15 kişisiyle mail aracılığıyla, 3 kişisiyle ise sosyal medya aracılığıyla iletişim kurularak veri toplanmıştır.

\section{Verilerin analizi}

Araştırma kapsamında elde edilen veriler içerik analizi kullanılarak analiz edilmiştir. İçerik analizi, özellikle sosyal bilimlerde kullanılan ve insan doğasını belirleme üzerine doğrudan olmayan yollarla çalışmaya imkân tanıyan tekniktir. Araştırmaya katılan öğretmenlerin her birine kodlar verilmiş ve verdikleri cevaplar tablolara işlenerek sunulmuştur. Verilerin yorumlanmasında verilen cevapların frekans değerleri dikkate alınmıştır. Yapılan 
analizin geçerlik ve güvenirliğini sağlamak için içerik analizi iki farklı araştırmacı yapılmış ve iki analiz arasındaki farklılıklar tartışılarak analize son şekli verilmiştir.

\section{Bulgular ve Yorum}

$\mathrm{Bu}$ bölümde, araştırma kapsamında elde edilen veriler sistematik hale getirilerek sunulacaktır. Bu bölüm iki kısımdan oluşmaktadır. Birinci kısımda öğretmenlerin demografik özellikleri tanıtılmış ve yeni Hayat Bilgisi Öğretim Programına hakimiyetlerine ilişkin bulgular sunulmuştur. Bu bölümün ikinci kısmını ise sınıf öğretmenlerinin Hayat Bilgisi Öğretim Programına ilişkin görüşlerine ilişkin bulgular oluşturmaktadır.

Araştırmanın verilerinin toplandığı gurubun demografik özelliklerinden bahsedilecek olursa, bu araştırmaya katılan sınıf öğretmenlerinin 25'i kadın, 13'ü erkek olup, 33’ü 1-5 yıl arası deneyime sahipken 5'i 6 yıl ve daha çok deneyime sahiptir. Bu öğretmenlerin 14'ü birleştirilmiş sınıflarda görev yapmaktayken, 24’ü müstakil sınıflı okullarda görev yapmaktadir.

Araştırmaya katılan öğretmenlerin Hayat Bilgisi Öğretim Programına hakim olup olmadıklarını belirlemek için, beş soru sorulmuştur. Öğretmenlere yöneltilen sorular ve öğretmenlerin cevapları Tablo 1'de sunulmuştur.

Tablo 1. Sınıf öğretmenlerinin Hayat Bilgisi Öğretim Programına dair yeterlilikleri

\begin{tabular}{|c|c|c|c|}
\hline Öğretmenlere Yöneltilen Sorular & Evet & Kismen & Hayır \\
\hline & $\mathbf{f}$ & $\mathbf{f}$ & $\mathbf{f}$ \\
\hline Program hazırlama komisyonlarına katıldınız mı? & 0 & 0 & 38 \\
\hline Tanıtım kurs ve seminerlere katıldınız mı? & 30 & 0 & 8 \\
\hline Yeni programı yeterince inceleyebildiniz mi? & 11 & 10 & 17 \\
\hline Yeni program sizlere yeterince tanıt $1 \mathrm{ld}_{1} \mathrm{~m} 1$ ? & 13 & 9 & 16 \\
\hline $\begin{array}{l}\text { Yeni programı uygulamak için yeterli materyaliniz var } \\
\text { mı? }\end{array}$ & 4 & 2 & 32 \\
\hline
\end{tabular}


Tablo1'de görüldüğü gibi öğretmenlerin hiçbiri program hazırlama komisyonlarına katılmamıştır. Öğretmenlerin büyük çoğunluğu programa yönelik tanıtım kurs ve seminerlerine katılmış olup, bu öğretmenlerin sekizi bu kurs ve seminerlere katılmamıştır. Öğretmenlerin yaklaşık yarısı öğretim programını yeterince inceleyemediğini belirtmiş olup, 11 öğretmen yeterince incelediğini belirtmiş, 10 öğretmen ise kısmen inceleyebildiğini belirtmiştir. Öğretmenlerin çoğu yeni öğretim programının kendilerine yeterince tanıtılmadığını düşünmekle birlikte bu öğretmenlerin 13'ü öğretim programının yeterince tanıtıldığını düşünmektedirler. Araştırmaya katılan öğretmenlerin çok büyük bir çoğunluğu programı uygulamak için yeterince materyalleri olmadığını belirtmişlerdir.

$\mathrm{Bu}$ verilerden hareketle araştırmaya katılan öğretmenlerin hiçbirinin program hazırlama komisyonlarına katılmadığı, büyük çoğunluğunun tanıtım kurs ve seminerlerine katıldığı, buna karşın büyük çoğunluğunun programı yeterince inceleyemediği ve programın kendilerine yeterince tanıtılmadığını düşünmekte olup, bu programı uygulamak için yeterli materyallerinin olmadığını düşünmektedirler.

Araştırmaya katılan sınıf öğretmenlerine yeni Hayat Bilgisi Öğretim Programı ile eski program arasında hangi farklılıkların olduğu sorulmuş olup, öğretmenlerin verdiği cevaplar Tablo 2'de sunulmuştur.

Tablo 2. Yeni Hayat Bilgisi Öğretim Programı ile eski program arasındaki farklılıklar

\begin{tabular}{|c|c|c|}
\hline Öğretmen Cevapları & Öğretmen Kodları & Frekans \\
\hline Kazanım sayısı azaltılmıştır & 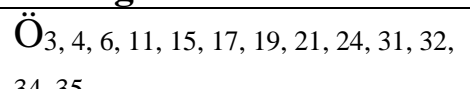 & 13 \\
\hline Önemli bir değişiklik yapılmamıştır & $\begin{array}{l}34,35 \\
\ddot{O}_{7,10,22,23,25,31}\end{array}$ & 6 \\
\hline Program sadeleştirilmiştir & $\ddot{O ̈}_{18,25,27,31,38}$ & 5 \\
\hline Kazanımlar sadeleştirilmiştir & $\ddot{\mathrm{O}}_{1,11,16,21,31}$ & 5 \\
\hline Kazanımların uygulanabilirliği artmıştır & $\ddot{O}_{1,21,32,34}$ & 4 \\
\hline Günlük yaşamla ilişkilendirme daha fazla & $\ddot{O}_{5,8,12,28}$ & 4 \\
\hline İçeriğin yoğunluğu azaltılmıştır & $\ddot{O}_{9,14,27,35}$ & 4 \\
\hline Ders saatlerinde değişiklik yapılmıştır & $\ddot{\mathrm{O}}_{13,15,17}$ & 3 \\
\hline Tema yerine üniteler getirilmiş & $\ddot{O}_{11,19}$ & 2 \\
\hline Yeterli bilgiye sahip değilim & $\ddot{O}_{20,37}$ & 2 \\
\hline Değer eğitimine daha fazla önem verilmiştir & $\ddot{\mathrm{O}}_{24,34}$ & 2 \\
\hline $\begin{array}{l}\text { Bireysel etkinlikler yerine grupla etkinlikler } \\
\text { getirilmiștir }\end{array}$ & $\ddot{\mathrm{O}}_{2}$ & 1 \\
\hline Yeni beceriler eklenmiştir & $\ddot{\mathrm{O}}_{6}$ & 1 \\
\hline Kazanım sayısı artırılıştır & $\ddot{\mathrm{O}}_{22}$ & 1 \\
\hline Boş & $\ddot{\mathrm{O}}_{26,29,30,33,34,36}$ & 5 \\
\hline
\end{tabular}


Tablo 2’de görüldüğü gibi 13 öğretmen kazanım sayısının azaltıldığını, altı öğretmen önemli bir değişikliğin yapılmadığını, beşer öğretmen programın ve kazanımların sadeleştirildiğini, dörder öğretmen kazanımların uygulanabilirliğinin artırıldığını, içerik yoğunluğunun azaltıldığını, günlük hayatla ilişkilendirmenin daha fazla yapıldığını, üç öğretmen ders saatlerinde değişiklik yapıldığını, ikişer öğretmen tema yerine ünitelerin getirildiğini, değer eğitimine daha fazla önem verildiğini, birer öğretmen ise bireysel etkinlikler yerine gurupla etkinliklerin getirildiğini, yeni becerilerin eklendiğini ve kazanım sayısının da artırıldığgnı belirtmiş olup, iki öğretmen yeterli bilgiye sahip olmadığını belirtip cevap vermemişken, 5 öğretmen farklılık belirtmemiştir.

Elde edilen bulgulara göre Hayat Bilgisi Öğretim Programında kazanımların azaltıldığı, programın ve kazanımların sadeleştirildiği, kazanımların uygulanabilirliğinin artırıldığı, programın içerik yoğunluğunun azaltıldığı, tematik yaklaşımdan vazgeçilerek ünite yapısının geri getirildiği, konuların günlük yaşamla ilişkisinin öncekine oranla daha kolay olduğu, öğrenciden beklenen beceri sayısının artırıldığı, değer eğitimine önceki programa oranla daha fazla önem verildiği ve etkinliklerin bireysellikten çok gurupla çalışmayı gerektirecek şekilde düzenlendiği söylenebilir.

Araştırmaya katılan sınıf öğretmenlerine yeni Hayat Bilgisi Öğretim Programındaki en önemli değişikliklerin neler olduğu ve bu değişikliklerin öğrenciye nasıl yansıyacağını düşündükleri sorulmuş ve elde edilen bulgular Tablo 3'de sunulmuştur.

Tablo3. Önemli değişiklikler ve bu değişikliklerin öğrenciye yansımaları

\begin{tabular}{|c|c|c|c|c|c|}
\hline $\begin{array}{l}\text { Önemli } \\
\text { Değişiklikler }\end{array}$ & $\begin{array}{l}\text { Öğretmen } \\
\text { Kodları }\end{array}$ & Frekans & $\begin{array}{l}\text { Öğrenciye } \\
\text { Yansıması }\end{array}$ & $\begin{array}{l}\text { Öğretmen } \\
\text { Kodları }\end{array}$ & Frekans \\
\hline $\begin{array}{l}\text { Programın } \\
\text { sadeleştirilmesi }\end{array}$ & $\begin{array}{l}\ddot{\mathrm{O}}_{5,9}, 11,14 \\
, 19,25,27,37\end{array}$ & 8 & $\begin{array}{l}\text { Daha hızlı öğrenme } \\
\text { sağlar }\end{array}$ & $\begin{array}{l}\ddot{O}_{1}, 5,11,12, \\
21,25,32,35,37\end{array}$ & 9 \\
\hline $\begin{array}{l}\text { Dersler günlük } \\
\text { yaşamla kolay } \\
\text { ilişkilendiriliyor }\end{array}$ & $\begin{array}{l}\ddot{O}_{4,15}, 18,28, \\
34\end{array}$ & 5 & $\begin{array}{l}\text { Anlamlı öğrenme } \\
\text { sağlar }\end{array}$ & $\mathrm{Ö}_{17,18,34,37}$ & 4 \\
\hline $\begin{array}{l}\text { Kazanımlar } \\
\text { sadeleştirilmiş }\end{array}$ & $\mathrm{Ö}_{1,13,21,32}$ & 4 & $\begin{array}{l}\text { Öğrencinin } \\
\text { becerilerini } \\
\text { geliştirir }\end{array}$ & Ö$_{6,15,24,28}$ & 4 \\
\hline $\begin{array}{l}\text { Öğrenci merkezli } \\
\text { olması }\end{array}$ & $\ddot{O}_{6,12,} 32$ & 3 & $\begin{array}{l}\text { Ö̈̆renmenin } \\
\text { etkililiği artmış }\end{array}$ & $\ddot{O}_{3,14,19,27}$ & 4 \\
\hline
\end{tabular}




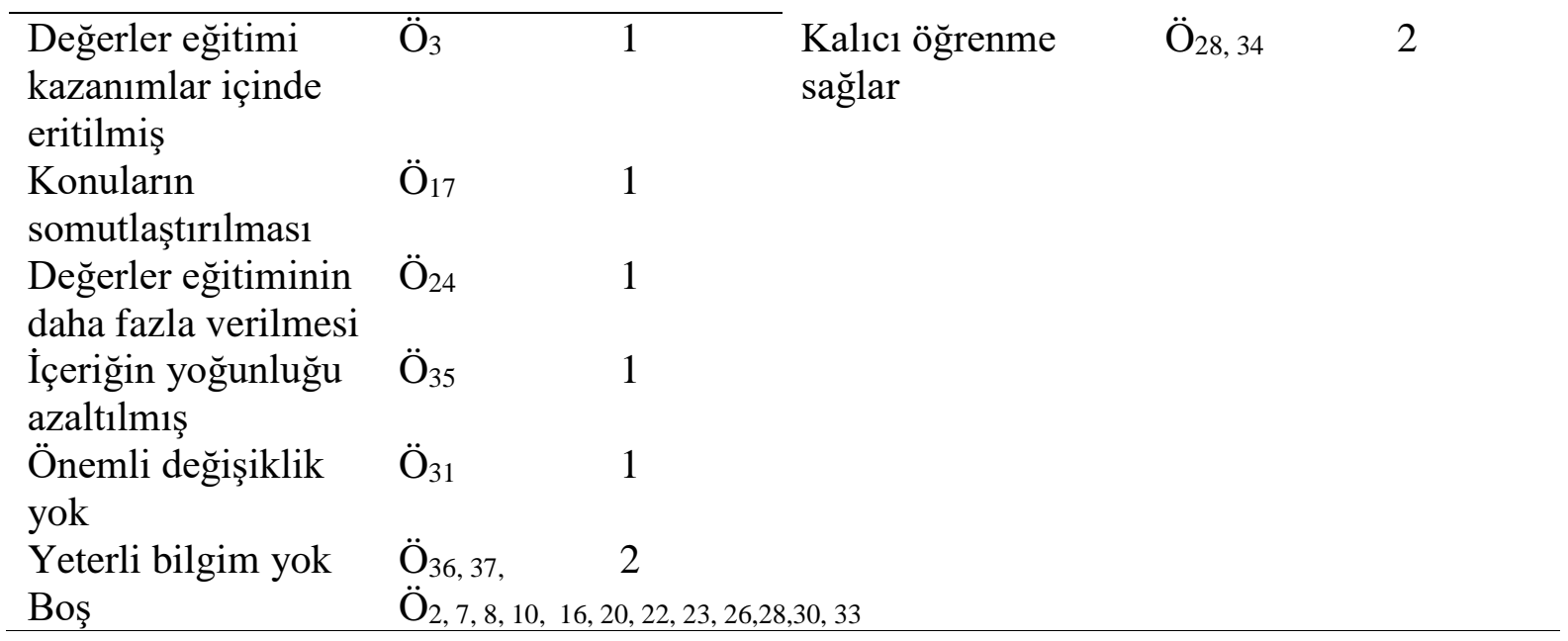

Tablo 3'e göre öğretmenlerin sekizi programın sadeleştirilmesini en önemli değişiklik olarak belirtmiştir. Beş öğretmen derslerin günlük yaşamla daha kolay ilişkilendirilebilmesini, dört öğretmen kazanımların sadeleştirilmesini, üç öğretmen programın öğrenci merkezli olmasını, birer öğretmen ise değerler eğitiminin kazanımların içinde eritilmesini, konuların somutlaştırılmasını, değerler eğitimine daha fazla yer verilmesini, içerik yoğunluğunun azaltılmasını en önemli değişiklik olarak belirtmiş̧ir.

Araştırmaya katılan öğretmenler programın ve kazanımların sadeleştirilmesini, yeni programın daha çok öğrenciyi merkeze almasını, derste öğrenilenlerin hayata aktarımının daha kolay hale getirilmesini, değer eğitiminin daha önemli hale getirilmesini ve kazanımlar içinde eritilmesini en önemli değişiklikler olarak görmektedirler.

Tablo 3'e göre öğretmenlerin önemli gördüğü bu değişikliklerin öğrencilere yansımaları hususunda dokuz öğretmen bu değiş̧ikliklerin daha hızlı öğrenmeyi sağlayacağı belirtilmiştir. Dörder öğretmen bu değişikliklerin anlamlı öğrenmeyi sağlayacağını, öğrenmenin etkililiğini artıracağını, öğrencilerin becerilerini geliştireceğini belirtmiş olup, iki öğretmen kalıcı öğrenmeyi sağlayacağını belirtmişlerdir.

Araştırmaya katılan öğretmenlerin belirttiği hızlı öğrenmeyi sağlaması, anlamlı öğrenmeyi sağlaması, öğrenmenin etkinliğini artırması, öğrencinin becerilerini geliştirmesi ve kalıcı öğrenmeyi sağlaması açısından bakıldığında, programda yapılan bu değişikliklerin öğrenciye olumlu yansıyacağını düşündükleri söylenebilir. 
Araştırmaya katılan sınıf öğretmenlerine yeni programın uygulanması açısından eski programa göre hangi kolaylık ve zorlukları getireceği sorulmuş olup, öğretmenlerin verdiği cevaplar Tablo 4'de sunulmuştur.

Tablo 4. Yeni programın uygulanmasının getireceği kolaylık ve zorluklar

\begin{tabular}{|c|c|c|c|c|c|}
\hline Kolaylık & $\begin{array}{l}\text { Öğretmen } \\
\text { Kodları }\end{array}$ & Frekans & Zorluk & $\begin{array}{l}\text { Öğretmen } \\
\text { Kodları }\end{array}$ & Frekans \\
\hline $\begin{array}{l}\text { Konuların } \\
\text { zamanında } \\
\text { yetiştirilebilmesi }\end{array}$ & $\begin{array}{l}\ddot{\mathrm{O}}_{1,} \\
3,8,13,20,37\end{array}$ & 6 & $\begin{array}{l}\text { Kazanımların } \\
\text { birleştirilmesi içeriği } \\
\text { yoğunlaştırmış }\end{array}$ & $\ddot{0 ̈}_{1,15,20,25,33,37}$ & 6 \\
\hline $\begin{array}{l}\text { Ortaya ürün } \\
\text { çıkarmak kolay }\end{array}$ & $\ddot{\mathrm{O}}_{2,9,11,16,23}$ & 5 & Sınıf yönetimi & $\ddot{O}_{2,16,19,23,26}$ & 5 \\
\hline $\begin{array}{l}\text { Kazanımların } \\
\text { artırılması }\end{array}$ & $\ddot{O}_{4,10,12}$ & 3 & $\begin{array}{l}\text { Öğretimde bölgesel } \\
\text { farklılıklar oluşturur }\end{array}$ & $\ddot{O}_{3,18,21,28,31}$ & 5 \\
\hline $\begin{array}{l}\text { Görselliğin } \\
\text { artırılması }\end{array}$ & $\ddot{\mathrm{O}}_{4,10,12}$ & 3 & $\begin{array}{l}\text { Materyal eksikliği } \\
\text { içeriğin } \\
\text { uygulanmasını } \\
\text { zorlaştırıyor }\end{array}$ & $\ddot{O ̈}_{4}, 5,30,35,37$ & 5 \\
\hline $\begin{array}{l}\text { Daha somut } \\
\text { örneklerin } \\
\text { bulunması }\end{array}$ & $\ddot{O}_{5,18,31}$ & 3 & $\begin{array}{l}\text { Ders saatinin az } \\
\text { olması sebebiyle } \\
\text { konular yetişmiyor }\end{array}$ & $\ddot{O ̈}_{5,10,12,20}$ & 4 \\
\hline $\begin{array}{l}\text { Etkinliklerle } \\
\text { konunun kolay } \\
\text { pekiştirilmesi }\end{array}$ & $\ddot{\mathrm{O}}_{7,8,13}$ & 3 & $\begin{array}{l}\text { Bazı etkinliklerin } \\
\text { öğrenciye zor gelmesi }\end{array}$ & $\ddot{0}_{7,10,18,31}$ & 4 \\
\hline $\begin{array}{l}\text { Öğrenci } \\
\text { merkezli olması }\end{array}$ & $\ddot{\mathrm{O}}_{7,9}$ & 2 & $\begin{array}{l}\text { Anlatım gücünün } \\
\text { gelişmemesi }\end{array}$ & $\ddot{O ̈}_{7,16,25}$ & 3 \\
\hline $\begin{array}{l}\text { Konuların } \\
\text { kavratılmasının } \\
\text { daha kolay } \\
\text { olması }\end{array}$ & $\mathrm{O}_{7}$ & 1 & $\begin{array}{l}\text { Bazı etkinliklerin } \\
\text { sikıcı olması }\end{array}$ & $\ddot{0 ̈}_{7,18,31}$ & 3 \\
\hline $\begin{array}{l}\text { Etkinliklerin } \\
\text { daha eğlenceli } \\
\text { olması }\end{array}$ & $\ddot{\mathrm{O}}_{7}$ & 1 & & & \\
\hline Boş & 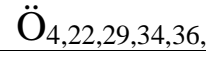 & & & & \\
\hline
\end{tabular}

Tablo 4'e göre araştırmaya katılan sınıf öğretmenlerinin sekizi yeni hayat bilgisi öğretim programının uygulamasının getireceği kolaylık olarak konuların zamanında yetiştirilebilmesini belirtmişlerdir. Öğretmenlerin beşi ortaya ürün çıkarmanın daha kolay olduğunu, üçer öğretmen kazanımların artırılmasını, görselliğin artırılmasını, daha somut örneklerin yer almasını, etkinliklerle konunun daha kolay pekiştirilmesini kolaylık olarak görmekte olup, iki öğretmen programın öğrenci merkezli olmasını, birer öğretmen ise 
konuların kavratılmasını ve etkinliklerin daha eğlenceli olmasını yeni programın getireceği kolaylıklar olarak belirtmişlerdir.

$\mathrm{Bu}$ bulgulardan hareketle öğretmenlerin, konuların zamanında yetiştirilebileceğini en önemli kolaylık olarak gördükleri bunun yanında yeni program ile ortaya bir ürün çıkarmanın daha kolay olduğunu, görselliğin artırılarak daha somut örnekler verilmiş olmasını, etkinliklerin daha eğlenceli olup, öğrenilenlerin pekiştirilmesini sağladığını düşünmektedirler.

Tablo 4'e göre öğretmenlerin belirttiği zorluklardan ise altı öğretmenin belirttiği kazanımların birleştirilmesinin içeriği yoğunlaştırması ön plana çıkan zorluk olmuştur. Beşer öğretmen yeni programın uygulanması ile sınıf yönetiminin daha zor olduğunu, öğretimde bölgesel farklılıkların oluşacağını, materyal eksikliklerinin programın uygulanmasını zorlaştıracağını, dörder öğretmen ders saatinin az olması sebebiyle konunun yetişmeyeceğini, bazı etkinliklerin öğrencilere zor geleceğini, üçer öğretmen ise anlatım gücünün gelişmeyeceğini ve bazı etkinliklerin öğrenciye sıkıcı geleceğini zorluk olarak belirtmiştir.

Bulgulardan hareketle kazanımların birleştirilmesinin içeriği yoğunlaştırdığı, sınıf yönetiminin daha da zorlaştığı, öğretimde bölgeler arası farklılıkların oluşabileceği, materyal eksiklikleri sebebiyle programın tam olarak uygulanmasının mümkün olmayacağı, bazı etkinliklerin sıkıcı olması ve ders saatlerinin içerik için yetersiz oluşu öğretmenler tarafindan belirtilen yeni programın getireceği en önemli zorluklardır.

Araştırmaya katılan öğretmenlere yeni programda Hayat Bilgisi derslerine yeterince önem verilip verilmediği ve bu dersin öğrencilerin gelişimi için öneminin ne olduğu sorulmuş olup öğretmenlerden elde edilen cevaplar Tablo 5'de sunulmuştur.

Tablo 5. Hayat Bilgisi dersinin önemi

\begin{tabular}{|c|c|c|c|c|c|}
\hline Cevap & $\begin{array}{l}\text { Öğretme } \\
\text { n Kodu }\end{array}$ & Frekans & Öğretmen Cevabı & $\begin{array}{l}\text { Öğretmen } \\
\text { Kodu }\end{array}$ & $\begin{array}{l}\text { Freka } \\
\text { ns }\end{array}$ \\
\hline \multirow[t]{8}{*}{ Evet } & $\ddot{\mathrm{O}}_{3,4,6,7,8,9,1}$ & 28 & Öğrencileri hayata hazırlar & $\ddot{\mathrm{O}}_{4,6,7,8,10,11,12,13,14}$ & 22 \\
\hline & $0,11,12,13,14,1$ & & & 15,17,18,19,20,20,24,25, & \\
\hline & $5,17,18,19,21,2$ & & & $26,31,33,34,37$ & \\
\hline & $2,23,24,25,26,2$ & & & & \\
\hline & $8,29,32,33,34,3$ & & & & \\
\hline & 7,38 & & & & \\
\hline & & & $\begin{array}{l}\text { Temel yaşam becerileri } \\
\text { gelișir }\end{array}$ & $\mathrm{O}_{1,2,3,4,7,21,23,27,36}$ & 9 \\
\hline & & & Topluma uyum sağlatır & $\ddot{\mathrm{O}}_{5,9,30,38}$ & 4 \\
\hline
\end{tabular}




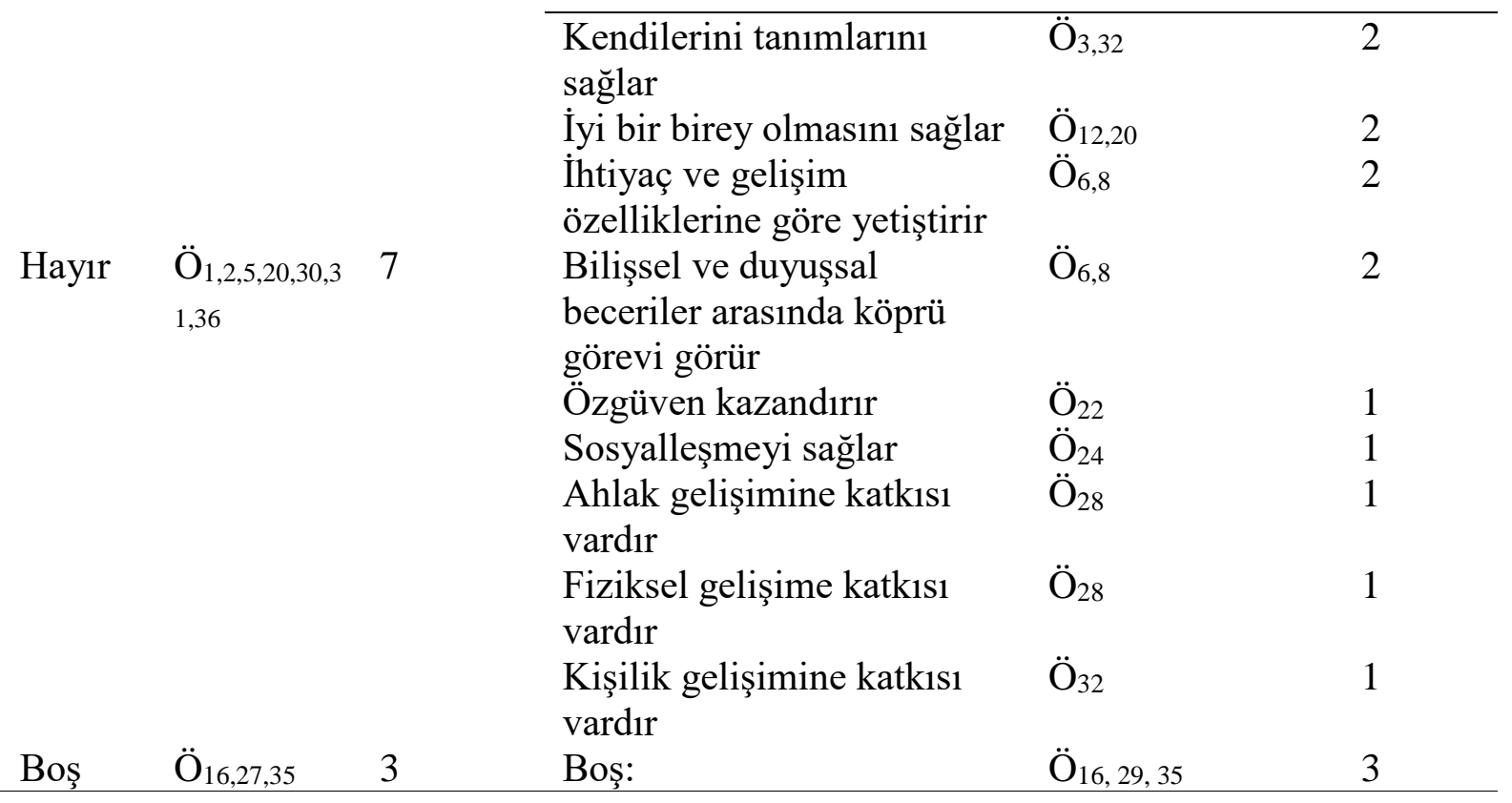

Tablo 5’e göre 28 öğretmen hayat bilgisi dersine yeni öğretim programında yeterince önem verildiğini düşünürken 3 öğretmen yeterince önem verilmediğini düşünmektedir. Tablo incelendiğinde 22 öğretmen hayat bilgisi dersinin öğrenciyi hayata hazırladığını, dokuz öğretmen bu dersin öğrenciye temel yaşam becerileri kazandırdığını, dört öğretmen öğrencinin topluma uyumunu sağladığını, ikişer öğretmen, öğrencinin, iyi bir birey olmasını, kendisini tanımasını, ihtiyaç ve gelişim özelliklerine göre yetişmesini, bilişsel ve duyuşsal özellikleri arasında köprü görevi gördüğünü belirtmiş olup, birer öğretmen, öğrenciye özgüven kazandırdığını, öğrencinin sosyalleşmesini sağladığını, öğrencinin ahlak gelişimine katkısı olduğunu, öğrencinin fiziksel gelişimine ve kişilik gelişimine katkısı olduğunu belirtmiştir.

$\mathrm{Bu}$ bulgulardan hareketle öğretmenlerin yeni öğretim programında hayat bilgisi dersine yeterince önem verildiğini düşündükleri, hayat bilgisi dersinin öğrenciyi hazırlaması, temel yaşam becerisi kazandırması, topluma uyum sağlayıp iyi bir birey olması, kendisini tanıması, ihtiyaç ve gelişim özelliklerine göre yetişmesine katkısı olması, özgüvenini desteklemesi, sosyalleşmesini sağlaması, fiziksel, kişilik ve ahlak gelişimi acısından destek olması sebepleriyle öğrenci açısından önemli bir ders olarak görmektedirler.

Araştırmaya katılan öğretmenlere yeni hayat bilgisi programı ile Hayat Bilgisi dersinin gerçek hayatla bağlantı kurulup kurulamadığını belirtmeleri ve açıklamaları istenilmiş olup, öğretmenlerin verdikleri cevaplar Tablo 6'da sunulmuştur. 
Tablo 6. Hayat Bilgisi dersinin gerçek hayat ile ilişkisi

\begin{tabular}{|c|c|c|c|}
\hline Cevap & Öğretmen Cevabı & Öğretmen Kodları & Frekans \\
\hline \multirow{4}{*}{ Evet } & $\begin{array}{l}\text { Öğrenci ders konuları ile günlük } \\
\text { hayatta karșılaşmaktadır }\end{array}$ & $\begin{array}{l}\ddot{\mathrm{O}}_{6,7}, 8,10,11,12,14,17,18,19,20,21,24,26 \text {, } \\
27,28,31,32,34,38\end{array}$ & 20 \\
\hline & Konular hayatın içindendir & $\ddot{\mathrm{O}}_{4,6,8,10,15,28,38}$ & 7 \\
\hline & $\begin{array}{l}\text { Temel yaşam becerileri } \\
\text { kazandırıyor }\end{array}$ & $\ddot{O ̈}_{9,19}$ & 2 \\
\hline & Kazanımlar somutlaştırılmış & $\ddot{O ̈}_{13,20}$ & 2 \\
\hline \multirow{5}{*}{ Hayır } & $\begin{array}{l}\text { Kitap örneği ile günlük yaşantı } \\
\text { benzeşmiyor }\end{array}$ & $\ddot{\mathrm{O}}_{5,22,25,36,37}$ & 5 \\
\hline & Kazanımların soyut olması & $\ddot{O}_{1,3}$ & 2 \\
\hline & Günlük yaşama aktarılamaması & $\ddot{O}_{1,3}$ & 2 \\
\hline & $\begin{array}{l}\text { Program köy çocuklarına uygun } \\
\text { örnekler içermiyor }\end{array}$ & $\ddot{\mathrm{O}}_{2}$ & 1 \\
\hline & $\begin{array}{l}\text { Çocuğun düzeyine uygun } \\
\text { olmayan içerik var }\end{array}$ & $\ddot{O}_{23}$ & 1 \\
\hline Boş & & $\ddot{O}_{16,29,30,33,35}$ & 5 \\
\hline
\end{tabular}

Tablo 6’ya göre öğretmenlerin büyük çoğunluğu yeni Hayat Bilgisi programının Hayat Bilgisi dersinin gerçek hayatla bağlantı kurmada önemli olduğunu belirtmiş olup, 20 öğretmen öğrencilerin ders konuları ile günlük hayatta karşılaştıklarını, yedi öğretmen konuların hayatın içinden olduğunu, ikişer öğretmen bu dersin öğrencilere temel yaşam becerileri kazandırdığını ve kazanımların somutlaştırıldığını belirtmişlerdir. Yeni Hayat Bilgisi programının Hayat Bilgisi dersinin gerçek hayatla bağlantı kurmada yetersiz olduğunu belirten öğretmenlerin beşi kitaplarda yer alan örneklerin günlük yaşantı ile benzeşmediğini, ikişer öğretmen kazanımların soyut olmasını, yaşama aktarımın zor olduğunu, birer öğretmen ise programın köy çocuklarına uygun olmadığını ve çocukların düzeyine uygun olmayan içerikler olduğunu belirtmişlerdir.

$\mathrm{Bu}$ bulgulardan hareketle, öğretmenlerin büyük çoğunluğunun yeni Hayat Bilgisi programının Hayat Bilgisi dersinin hayata aktarım noktasında yeterli olduğunu düşündükleri ve programda yer alan Hayat Bilgisi dersinde öğrencilerin öğrendiklerinin günlük hayatta karşılaştıkları, hayatın içinden şeyler olduğu, bu dersin öğrencinin temel yaşam becerileri kazandırmada önemli olduğu öğretmenler tarafindan ortaya koyulmuştur. Ancak buna karşın bazı öğretmenlerin program çerçevesinde hazırlanan ders kitabındaki örneklerin günlük yaşamla benzeşmediğini, kazanımların soyut olduğunu ve bu sebeple yaşama aktarımının zor 
olduğunu, program içeriğinde öğrenci düzeyine uygun olmayan içerik bulunduğunu ve bu programın köy çocuklarına uygun olarak düzenlenmediğini düşündükleri söylenebilir.

Araştırmaya katılan öğretmenlere yeni Hayat Bilgisi Öğretim Programında gördükleri eksikliklerin neler olduğu ve bu eksikliklerin giderilmesi için neler önerdikleri sorulmuş ve elde edilen cevaplar Tablo 7'de sunulmuştur.

Tablo7. Yeni Hayat Bilgisi Öğretim Programındaki eksiklikler ve öneriler

\begin{tabular}{|c|c|c|}
\hline Öğretmen Cevapları & $\begin{array}{l}\text { Öğretmen } \\
\text { Kodları }\end{array}$ & Frekans \\
\hline $\begin{array}{l}\text { Her coğrafi bölgede uygulanabilir olarak düzenlenmesi } \\
\text { gerekir }\end{array}$ & $\begin{array}{l}\ddot{\mathrm{O}}_{2,6,8,10,11,15,21,} \\
32,35\end{array}$ & 9 \\
\hline Atatürk konularına daha çok yer verilmelidir & $\ddot{\mathrm{O}}_{3,5,9,16,20,29}$ & 6 \\
\hline Değişiklikler daha özele indirgenmelidir & $\ddot{O}_{1,12,18,26}$ & 4 \\
\hline Milli mücadeleye önem verilmelidir & $\ddot{\mathrm{O}}_{3,23,30}$ & 3 \\
\hline $\begin{array}{l}\text { İnsan hakları ve vatandaşlık konuları çocukların } \\
\text { seviyesine indirgenmelidir }\end{array}$ & $\mathrm{O}_{4,19,28}$ & 3 \\
\hline İçerik günlük yaşamla daha çok ilişkilendirilmelidir & $\ddot{\mathrm{O}}_{4,27,38}$ & 3 \\
\hline Müfredat sadeleştirilmelidir & $\ddot{\mathrm{O}}_{7,14,31}$ & 3 \\
\hline Konular basitleştirilmelidir & $\ddot{\mathrm{O}}_{7,24,36}$ & 3 \\
\hline Etkinliklerin eğlenceli ve anlaşılır olması sağlanmalıdır & $\ddot{\mathrm{O}}_{7}$ & 1 \\
\hline Örneklerin oyunlaştırılması gerekir & $\ddot{\mathrm{O}}_{7}$ & 1 \\
\hline Uygulamalar kolaylaştırılmalıdır & $\ddot{\mathrm{O}}_{13}$ & 1 \\
\hline $\begin{array}{l}\text { Kitaplar tüm Türkiye yaşam standartları düşünülerek } \\
\text { hazırlanmalıdır }\end{array}$ & $\ddot{\mathrm{O}}_{22}$ & 1 \\
\hline Konular ayrıntılı olarak işlenmelidir & $\ddot{O}_{25}$ & 1 \\
\hline Boș & $\ddot{\mathrm{O}}_{17,33,34,37}$ & 4 \\
\hline
\end{tabular}

Tablo 7'ye göre dokuz öğretmen yeni Hayat Bilgisi Öğretim Programının her coğrafi bölge göz önünde bulundurularak yeniden düzenlenmesi gerektiğini, altı öğretmen Atatürk konularına daha çok yer verilmesi gerektiğini, dört öğretmen değişikliklerin daha özele indirilmesi gerektiğini, üçer öğretmen milli mücadele konularına daha fazla önem verilmesi gerektiğini, insan hakları ve vatandaşlık konularının çocukların seviyesine uygun hale getirilmesi gerektiğini, program içeriğinin günlük yaşamla daha çok ilişkilendirilmesi gerektiğini, programın daha da sadeleştirilmesi gerektiğini, konuların basitleştirilmesi gerektiğini, birer öğretmen ise etkinliklerin eğlenceli ve anlaşılır olması gerektiğini, programda yer alan örneklerin oyunlaştırılması gerektiğini, uygulamaların kolaylaştırılması gerektiğini, ders kitaplarının tüm Türkiye yaşam standartları düşünülerek hazırlanması gerektiğini, konuların daha ayrıntılı olarak işlenmesi gerektiğini belirtmişlerdir. 
Araştırmaya katılan sınıf öğretmenlerinin yeni Hayat Bilgisi Öğretim Programının ülkenin her coğrafi bölgesi dikkate alınarak tekrar hazırlanması gerektiğini, milli mücadele ve Atatürk konularına daha çok yer verilmesi gerektiğini, insan hakları ve vatandaşlık konularının çocukların düzeyine indirgenerek yeniden düzenlenmesi gerektiğini, program içeriğinin günlük yaşamla daha ilişkili hale getirilmesi gerektiğini, programın sadeleştirilerek konuların daha basit hale getirilmesi gerektiğini, program içeriğindeki etkinliklerin daha anlaşılır ve eğlenceli hale getirilmesi gerektiğini düşündükleri söylenebilir.

Araştırmaya katılan öğretmenlere yöneltilen sorular haricinde herhangi bir ekleme yapmak isteyip istemedikleri sorulmuş olup, ekleme yapmak isteyenlerin cevapları Tablo 8'de sunulmuştur.

Tablo 8. Öğretmenlerin görüş ve önerileri

\begin{tabular}{lll}
\hline Öğretmen Cevapları & $\begin{array}{l}\text { Öğretmen } \\
\text { Kodları }\end{array}$ & Frekans \\
\hline $\begin{array}{l}\text { Toplumun tüm kesimini ortak bir paydada toplayacak şekilde } \\
\text { düzenlenmeli }\end{array}$ & $\ddot{O ̈}_{22,36}$ & 2 \\
Öğretmenler kendi planlarını özgürce oluşturabilmeli & $\ddot{O ̈}_{1}$ & 1 \\
$\begin{array}{l}\text { Gerekli materyaller sağlanmalı } \\
\text { Hayat bilgisi ülkenin geleceğine 1şık tutacak şekilde tekrar }\end{array}$ & $\ddot{O ̈}_{7}$ & 1 \\
düzenlenmeli & Ö$_{20}$ & 1 \\
$\begin{array}{l}\text { Sürekli müfredat değişimi eğitim öğretimi olumsuz } \\
\text { etkilemektedir. Bu nedenle bu denli sık değişikliğine }\end{array}$ & Ö$_{23}$ & 1 \\
gidilmemeli & & \\
Hayat bilgisi içeriği öğrenci düzeyine uygun hale getirilmeli & $\ddot{O ̈}_{37}$ & 1 \\
\hline
\end{tabular}

Tablo 8'e göre öğretmenlerin ikisi öğretim programının toplumun tüm kesimlerini toplayacak şekilde düzenlenmesi gerektiğini, birer öğretmen ise öğretmenlerin kendi planlarını özgürce hazırlayabilmesi gerektiğini, programın gerektirdiği materyallerin temin edilmesi gerektiğini, Hayat Bilgisi dersinin ülkenin geleceğine 1 şık tutacak şekilde yeniden düzenlenmesi gerektiğini, bu dersin öğrenci düzeyine uygun hale getirilmesi gerektiğini ve sürekli müfredat değişiminin öğretimi olumsuz etkilemesinden dolayı, sıklıkla değişiklik yapılmaması gerektiğini belirtmişlerdir.

Bu bulgulardan hareketle, öğretim programının ülke şartları ve coğrafyası göz önünde bulundurularak yeniden düzenlenmesi gerektiği, öğretmenlere plan yapmada özgürlük tanınması gerektiğgi, programın öngördüğü materyallerin temin edilmesi gerektiği, sürekli 
program değişikliğinin öğretimi olumsuz etkilemesinden dolayı, sıklıkla değişiklik yapılmaması gerektiği söylenebilir.

\section{Tartışma, Sonuç Ve Öneriler}

$\mathrm{Bu}$ bölümde araştırma kapsamında elde edilen bulgulardan hareketle tartışma, sonuçlar ve öneriler sunulacaktır.

\section{Tartışma}

Araştırma sonucunda öğretmenlerin hiç birinin program hazırlama komisyonlarına katılmadığı ancak program tanıtım kurs ve seminerlerine büyük oranda katıldıklarını belirtmişlerdir. Program kurs ve seminerlerine katılmış olmalarına rağmen öğretmenlerin büyük bir kısmı programı yeterince inceleyemediğini belirtmiş olup, programın kendilerine yeterince tanıtılmadığını düşünmektedirler. Demirkol'un (2010) yapmış olduğu araştırmada, ilköğretim okullarında okul temelli hizmet içi eğitim etkinliklerinin tür, sıklık ve süre bakımından yetersiz olduğu, içerik ve süre açısından da çok kısıtlı olduğu ortaya çıkmıştır. Yine Baykan, Ercan ve Erdoğan (2011)'nın çalışmasında öğretmenlerin hizmet içi eğitimleri yeterli düzeyde almadıkları ve alınan hizmet içi eğitimlerin de daha çok kuramsal olduğu öğretmenler tarafindan belirtilmiştir. Bu durum, öğretmenlere verilen kurs ve seminerlerin istenilen amaca ulaşmada yetersiz olduğu sonucuna götürebilir. Ayrıca, öğretmenlerin yeni geliştirilen öğretim programları ile ilgili olumsuz görüşleri, öğretmenlerin ilk aşamada alışkanlıklarını değiştirme konusunda istekli olmamalarından kaynaklanabilir (Ornstein ve Hunkins, 1998).

Araştırmaya katılan öğretmenlerin bir kısmı kazanım sayısının azaltıldığını söylerken bir kısmı kazanım sayısının arttığını söylemişlerdir. 2017 Hayat Bilgisi Öğretim Programı incelendiğinde 1. Sınıflarda kazanım sayısının azaltıldı̆̆ı, 2. Sinıflarda artırıldı̆̆ı ve 3. Sınıflarda sabit tutulduğu görülmektedir. Bu durumda kazanım sayısının azaltıldığını söyleyen öğretmenler 1. Sınıf öğretmenleriyken, kazanım sayısının artırıldığını söyleyen öğretmenler 2. Sınıf öğretmenleridir denilebilir. Bu durum 2017 Hayat Bilgisi Öğretim Programıyla paralellik göstermektedir.

Öğretmenler kitaptaki örneklerle günlük hayatın benzeşmediğini düşünmektedirler. Ancak Korkmaz (2008), çalışmasında Birinci Sınıf Hayat Bilgisi Öğretim programında tema ve konuların çok iyi seçildiğini ve programa uygun ders kitaplarının iyi bir şekilde 
hazırlandığını ifade etmişlerdir. Bu farklılığın sebebi öğretmenin görev yaptığı yerin özelliklerinden kaynaklı olabilir.

Öğretmenler, programın ve kazanımların sadeleştirilmesi ve etkinliklerin daha eğlenceli hale getirilmesi gerektiğini belirtmişlerdir. Ancak Milli Eğitim Bakanlığının 18 Temmuz 2017 Tarihli Müfredat yenileme ve değişikliği üzerine yaptı̆̆ı basın açıklamasında öğretim programlarının sadeleştirilip, daha anlaşılabilir hale getirildiği belirtilmiştir. $\mathrm{Bu}$ farklılı̆̆ın sebebi öğretmenlerin programı yeterince incelememiş olmalarından kaynaklandığı söylenebilir.

Araştırma sonuçlarından bir başkası ise öğretmenler yeni Hayat Bilgisi Öğretim Programının Türkiye'nin bütün bölgelerini ve koşullarını kapsayacak şekilde yeniden düzenlenmesini istemektedirler. Korkmaz’a göre (2008), Türkiye'deki hızlı nüfus artışı ve göçlerden kaynaklanan kalabalık sınıflar sorunu tam olarak çözülememesi yeni programın ülke genelinde istenilen şekilde uygulanmasını zorlaştırmaktadır. Çünkü öğretmenler etkinliklerin fazla, sınıfların kalabalık, öğretmen gözlem formlarının çok fazla olması ve sürenin azlığından dolayı uygulamada güçlükler yaşadıklarını ifade etmişılerdir. Bu bulgudan hareketle yeni öğretim programlarının hazırlanırken bu durumun göz önünde bulundurulması gerekliliğini ortaya koymaktadır.

\section{Sonuç}

Araştırmaya katılan öğretmenlerin hiçbirinin program hazırlama komisyonlarına katılmadığ1, büyük çoğunluğunun tanıtım kurs ve seminerlerine katıldığı, buna karşın büyük çoğunluğunun programı yeterince inceleyemediği ve programın kendilerine yeterince tanıtılmadığını düşünmekte olup, bu programı uygulamak için yeterli materyallerinin olmadığını düşünmektedirler.

Araştırmaya katılan öğretmenler eski öğretim programına göre yeni Hayat Bilgisi Öğretim Programında kazanımların azaltıldığını, programın ve kazanımların sadeleştirildiğini, kazanımların uygulanabilirliğinin artırıldığını, programın içerik yoğunluğunun azaltıldığını, tematik yaklaşımdan vazgeçilerek ünite yapısının geri getirildiğini, konuların günlük yaşamla ilişkisinin öncekine oranla daha kolay olduğunu, öğrenciden beklenen beceri sayısının artırıldığını, değer eğitimine önceki programa oranla daha fazla önem verildiğini ve etkinliklerin bireysellikten çok gurupla çalışmayı gerektirecek şekilde düzenlendiğini 
belirtmişlerdir. $\mathrm{Bu}$ değişiklikler arasında öğretmenler, kazanımların sadeleştirilmesini, yeni programın daha çok öğrenciyi merkeze almasını, derste öğrenilenlerin hayata aktarımının daha kolay hale getirilmesini, değer eğitiminin daha önemli hale getirilmesini ve kazanımlar içinde eritilmesini en önemli değişiklikler olarak görmektedirler. Ayrıca araştırmaya katılan öğretmenlerin belirttiği hızlı öğrenmeyi sağlaması, anlamlı öğrenmeyi sağlaması, öğrenmenin etkinliğini artırması, öğrencinin becerilerini geliştirmesi ve kalıcı öğrenmeyi sağlaması açısından bakıldığında, programda yapılan bu değişikliklerin öğrenciye olumlu yansıyacağını düşünmektedirler.

Yeni Hayat Bilgisi Öğretim Programıyla öğretmenlerin, konuların zamanında yetiştirilebileceğini en önemli kolaylık olarak gördükleri bunun yanında yeni program ile ortaya bir ürün çıkarmanın daha kolay olduğunu, görselliğin artırılarak daha somut örnekler verilmiş olmasını, etkinliklerin daha eğlenceli olup, öğrenilenlerin pekiştirilmesini sağladığını düşünmektedirler. Aynı zamanda öğretmenlere göre, kazanımların birleştirilmesinin içeriği yoğunlaştırdığı, sınıf yönetiminin daha da zorlaştığı, öğretimde bölgeler arası farklılıkların oluşabileceği, materyal eksiklikleri sebebiyle programın tam olarak uygulanmasının mümkün olmayacağı, bazı etkinliklerin sıkıcı olması ve ders saatlerinin içerik için yetersiz oluşu öğretmenler tarafından belirtilen yeni programın getireceği en önemli zorluklardır.

Öğretmenlerin yeni öğretim programında hayat bilgisi dersine yeterince önem verildiğini düşündükleri, hayat bilgisi dersinin öğrenciyi hazırlaması, temel yaşam becerisi kazandırması, topluma uyum sağlayıp iyi bir birey olmasını sağlaması, kendisini tanıması, ihtiyaç ve gelişim özelliklerine göre yetişmesine katkısı olması, özgüvenini desteklemesi, sosyalleşmesini sağlaması, fiziksel, kişilik ve ahlak gelişimi acısından destek olması sebepleriyle öğrenci açısından önemli bir ders olarak görmektedirler. Ayrıca, öğretmenlerin büyük çoğunluğunun yeni Hayat Bilgisi programının Hayat Bilgisi dersinin hayata aktarım noktasında yeterli olduğunu düşündükleri ve programda yer alan Hayat Bilgisi dersinde öğrencilerin öğrendiklerinin günlük hayatta karşılaştıkları, hayatın içinden şeyler olduğu, bu dersin öğrencinin temel yaşam becerileri kazandırmada önemli olduğu öğretmenler tarafından ortaya koyulmuştur. Ancak buna karşın bazı öğretmenlerin program çerçevesinde hazırlanan ders kitabındaki örneklerin günlük yaşamla benzeşmediğini, kazanımların soyut olduğunu ve bu sebeple yaşama aktarımının zor olduğunu, program içeriğinde öğrenci düzeyine uygun 
olmayan içerik bulunduğunu ve bu programın köy çocuklarına uygun olarak düzenlenmediğini düşünmektedirler. Aynı zamanda araştırmaya katılan sınıf öğretmenlerinin yeni Hayat Bilgisi Öğretim Programının ülkenin her coğrafi bölgesi dikkate alınarak tekrar hazırlanması gerektiğini, Milli Mücadele ve Atatürk konularına daha çok yer verilmesi gerektiğini, insan hakları ve vatandaşlık konularının çocukların düzeyine indirgenerek yeniden düzenlenmesi gerektiğini, program içeriğinin günlük yaşamla daha ilişkili hale getirilmesi gerektiğini, programın sadeleştirilerek konuların daha basit hale getirilmesi gerektiğini, program içeriğindeki etkinliklerin daha anlaşılır ve eğlenceli hale getirilmesi gerektiğini düşünmektedirler. Bunlara ek olarak, öğretim programının ülke şartları ve coğrafyası göz önünde bulundurularak yeniden düzenlenmesi gerektiği, öğretmenlere plan yapmada özgürlük tanınması gerektiği, programın öngördüğü materyallerin temin edilmesi gerektiği, sürekli program değişikliğinin öğretimi olumsuz etkilemesinden dolayı sıklıkla değişiklik yapılmaması gerektiği söylenebilir.

\section{Öneriler}

- Öğretmenlerin program hazırlama süreçlerine daha fazla katılımı sağlanmalıdır.

- Yeni öğretim programı ile ilgili kurs ve seminerler ağırlık verilmeli ve öğretmenlerin yeni öğretim programını yeterince tanımaları ve anlamaları sağlanmalıdır.

- Programın öngördüğü araç-gereç ve materyaller öğretmenlerin kullanımına sunulmalıdir.

- Program daha katılımcı bir oluşumla yeniden hazırlanmalı ve bu yeni programda öğretmenlerin görüş ve isteklerine daha fazla önem verilmelidir.

- Öğretim programı tüm okul türlerini (müstakil sınıflı okul, köy okulu, birleştirilmiş sınıflı okul vs.) kapsayacak ve özelliklerine uygun olacak şekilde tekrar hazırlanmalı ya da revize edilmelidir.

\section{Makalenin Bilimdeki Konumu (Yeri)}

Temel Eğitim Bölümü/ Sınıf Öğretmenliği Eğitimi

\section{Makalenin Bilimdeki Özgünlüğü}


Bilindiği üzere okullardaki öğretim programları sıklıkla değişmektedir. Bu çalışmada, yapılan değişiklikler ile bu değişikliklere ilişkin programın uygulayıcısı olan öğretmenlerin görüşleri ortaya çıkarılmıştır. Ayrıca program hazırlama sürecinde öğretmenlerin etkinlik durumları da belirlenmiştir. Bu çalışmanın sonuçları Hayat Bilgisi Öğretim programında gelecekte yapılması olası değişikliklere 1şık tutabilecek nitelikte olması ve halihazırdaki programı uygulayıcılar gözünden ortaya koyulması yönleriyle önemli görülmektedir. Ayrıca bu çalışma, öğretmenlerin programla ilgili yeterliliklerinin ortaya koyulması çıkarılması bakımından önemlidir.

\section{Kaynakça}

Baykan, A.K., Ercan, U., \& Erdogan, M. (2011). Barriers and needs regarding the 1mplementation of new measurement and evaluation techniques; A review of research between 2005 and 2010. An oral presentation on First International Conference on Curriculum and Instruction[Tam Metin], 05-08 October, Anadolu University, Eskişehir.

Demirkol, M. (2010). İlköğretim okullarında öğretmenlere yönelik okul temelli hizmet içi eğitim etkinliklerinin değerlendirilmesi. Milli Ĕ̆itim Dergisi, 188, 158-173.

Fitcher, J. (2001). Sosyoloji Nedir?. Atilla Kitabevi. (Çev. Nilgün ÇELEBİ). Ankara.

Karkmaz, İ. (2008). Yeni ilköğretim birinci sınıf programının öğretmenler tarafından değerlendirilmesi. Education 192 (2).8-17.

Milli Eğitim Bakanlığı [MEB] (2005). İlköğretim 1-5. sınıf programları tanıtım el kitabı. Devlet Kitapları Müdürlüğü Basımevi. Ankara.

Milli Eğitim Bakanlığı [MEB] (2009). Talim ve Terbiye Kurulu Başkanlı̆̆ Öğretim Programları. Hayat Bilgisi Dersi Öğretim Programı. Ankara.

Milli Eğitim Bakanlığı [MEB] (2017). Talim ve Terbiye Kurulu Başkanlı̆̆ Öğretim Programları. Hayat Bilgisi Dersi Öğretim Programı. Ankara.

Ornstein, A. C.,\& Hunkins, F. P. (1998). Curriculum: Foundations, principles, and issues. Allyn and Backon.Boston. 
Özdemir, S. M. (2009). Eğitimde program değerlendirme ve Türkiye'de eğitim programlarını değerlendirme çalışmalarının incelenmesi. Yüzüncü Yıl Üniversitesi Eğitim Fakültesi Dergisi, 6(2), 126-149.

Tezcan, M. (1984). Sosyal ve Kültürel Değişme. Ankara Üniversitesi Basımevi. Ankara.

Turan, M. (2006). Yeni ilkögrretim programları. Gürol, M. (Ed.). Öğretimde planlama ve değerlendirme. (4. baskı). Akış Yayıncılık. Ankara.

Yazıcıŏ̆lu, Y. ve Erdoğan, S. (2004). Spss uygulamalı bilimsel araştırma yöntemleri. Detay Yayıncılık. Ankara.

Yıldırım, A. ve Şimşek, H. (2011).Sosyal bilimlerde nitel araştırma yöntemleri (8.Baskı), Seçkin, Ankara.

\section{Extented Summary}

\section{Aim and importance}

The necessary changes in education programs are undoubtedly influencing all relevant parties of the education and training activities. Since it is an individual at the center of education and training activities and closely related to all sections of the society, the changes made in this area should be done very carefully, carefully, planned and programmed. As a matter of fact, this change should be satisfactory to all sides of the educational activities, such as positive reflection of gathering, solution to existing problems or problems or reducing the effects of these problems. It is important to monitor the changes in the education system or the curriculum, which are such an important issue, to correct the incomplete or incorrect aspects and to correct them without losing time. From this point of view, what are the opinions of class teachers on the Life Science Program in this study? the answer will be searched. The purpose of studying this question is to determine the opinions of classroom teachers on the Life Science Teaching Program, which was changed in 2017. Within this scope, the following subobjectives will be tried to be answered; teachers, committees for preparing programs, and seminars for promotional courses, whether they can adequately review and examine the new program, whether there are enough materials to implement the new program, what are the differences between the new program and the old program and what are the most important changes brought about by the new program and how those changes will affect the student , 
what convenience and difficulties the new program will bring to the former in terms of implementation

\section{Method}

This study, which aims to determine the opinions of classroom teachers towards the Life Science Curriculum modified in 2017, is a case study based on the qualitative research approach. The reason for choosing this research method is that it is suitable for research purpose. Because, the changes made in the 2017 Life Science Curriculum are evaluated by the teachers. Snowball sampling method was used in the study. Within the scope of the study, firstly five teachers were contacted and the subjects were passed through them with the other teachers. Care was taken to ensure that these five teachers were from different regions, and no intervention was subsequently made. Within the scope of the study, 45 teachers were contacted, but because of the reluctance of the seven teachers, the study was conducted with 38 teachers. The data obtained in the study were collected by the researcher through semi-structured interviews. Semi-structured interview form 4 prepared by the researcher was reviewed by four different experts and opinions were taken and final form was given to the form. The geographical locations of the teachers working in the working group and their distance from each other were considered to be uneconomic with face to face meetings with each other. The interviews were made via phone, mail and social media by taking advantage of the opportunities of developing technology. 38 teachers participating in the survey were contacted by 20 persons via telephone, 15 people by mail and 3 people by social media. The data obtained in the study were analyzed using content analysis. Content analysis is a technique that is used in social sciences and allows people to work in ways that are not directly related to human nature. Each of the teachers who participated in the research were given codes and their answers were presented on a tablolar basis. The frequency values of the responses given in the interpretation of the data are taken into account.

\section{Discussion and Conclusion}

Most of the teachers who participated in the research think that most of the teachers did not participate in the program preparation commissions, the vast majority participated in the introduction courses and seminars but the vast majority could not sufficiently examine the 
program and that the program was not introduced to them adequately and they did not have enough materials to implement this program. According to the old curriculum, according to the old curriculum, the students are expected to learn that the gains are reduced in the new Life Science Curriculum, the program and gains are simplified, the applicability of the gains is increased, the content intensity of the program is reduced, the unit structure is restored by giving up the thematic approach, that the value education is more important than the previous program rate and that the activities are organized so that they need to work with many groups from individuality. Among these changes, teachers view simplification of achievements, centralization of the new program to more students, improvement of the transfer of the life of the learners, making the value education more important and dissolving in the gains as the most important changes. They also think that these changes made in the program will reflect the students positively, as determined by the teachers who participated in the research, providing rapid learning, providing meaningful learning, enhancing the effectiveness of the learners, improving the skills of the learners and ensuring permanent learning. With the new Life Science Teaching Program, teachers think that it is easier to produce a product with the new program, that they have given more concrete examples by increasing their visuality, that they have made the activities more fun and reinforced the learned ones. At the same time, according to the teachers, the combination of achievements intensified the content, the class management more difficult, the differences between the different regions in education could occur, the program could not be fully implemented due to lack of material, some activities were boring and the lesson times were insufficient for content. they are important difficulties. It is important for the teachers to have enough knowledge about life science lesson in the new curriculum, to prepare the student life lesson, to provide basic life skills, to be a good individual by harmonizing with the collective, to contribute to educating himself / herself according to needs and development characteristics, physical, personality and moral development of the students in terms of support for their suffering as an important lesson. In addition, it was revealed by teachers that the vast majority of the teachers think that the new Life Science program is sufficient for the transfer of life information, and that what they learn in the Life Science course in the program is something that they meet in daily life and that they learn from life. However, some teachers think that the examples in the course book are not similar to everyday life, that the achievements are abstract and that it is difficult to transfer to life, that there is inappropriate 
content in the program content and that this program is not organized for village children. At the same time, it has been observed that the teachers of the classrooms participating in the research should be reorganized by taking into consideration the geographical region of the country, the national struggle and the Atatürk issues should be more involved, the human rights and citizenship issues should be reduced to the level of children and reorganized, they need to be made simpler by making the program simpler, and the activities in the program content should be made more understandable and fun. In addition to these, it can be said that the curriculum should be rearranged considering the country conditions and geography, the teachers should be given freedom in making plans, the materials required by the curriculum should be provided, and the constant program change should not be changed frequently because it adversely affects teaching.

\section{Suggestions}

- More involvement of teachers in the curriculum development process should be ensured.

- Courses and seminars related to the new curriculum should be emphasized and teachers should adequately recognize and understand the new curriculum.

- The tools and materials prescribed by the program must be made available to teachers.

- The program should be reorganized with a more participatory approach and more emphasis should be placed on teachers' views and requests in this new program.

- The curriculum should be revised or revised to include all school types (independent classroom school, village school, unified classroom school, etc.) and to suit their specifications. 